\title{
One-of-a-Kind Production (OKP) Planning and Control: An Empirical Framework for the Special Purpose Machines Industry
}

\author{
Federico Adrodegari ${ }^{1}$, Andrea Bacchetti ${ }^{1}$, Alessandro Sicco ${ }^{1}$, Fabiana Pirola ${ }^{2}$, \\ and Roberto Pinto ${ }^{2}$ \\ ${ }^{1}$ Department of Mechanical and Industrial Engineering, University of Brescia, Italy \\ \{federico.adrodegari, andrea.bacchetti\} aing.unibs.it, \\ a.sicco@csmt.it \\ ${ }^{2}$ CELS - Department of Industrial Engineering, University of Bergamo, Italy \\ \{fabiana.pirola, roberto.pinto\} @unibg. it
}

\begin{abstract}
In this paper, we focus on the One-of-a-Kind Production (OKP) industry, where each product is designed and manufactured based on specific customer requirements to a large extent, according to an Engineer To Order (ETO) approach. This research has been carried out among the "SIGI-X" project, funded by the Italian Ministry of Economic Development (MISE). The paper illustrates an empirical study on the state-of-the-art of information systems supporting the leading processes in OKP companies. Through a set of 21 case studies in Italian companies producing special machines, we aim to: identify and investigate strengths and weaknesses of the main OKP business processes; analyze the ICT support and its level of integration among the different ICT solutions; identify levers for improvement, concerning organizational, methodological and informatics aspects; build a practical framework that could define and link the main processes in order to obtain a sort of guideline useful for reengineering the processes, and laying the foundation for a new integrated ICT business template for OKP companies. The lack of support of three fundamental tasks such as project management, planning and cost control underlines that there is substantial room for improvement under the ICT support perspective. Finally, the development of an integrated IT environment to support (in particular) project management and planning activities, specifically addressed to OKP context, would help these companies to improve their performance and competitiveness.
\end{abstract}

Keywords: One-of-a-Kind Production (OKP), Engineer To Order (ETO), Special Purpose Machines Industry, Production Planning \& Control (PPC).

\section{Introduction}

One-of-a-Kind Production (OKP) industry is characterized by a low level of repetitiveness, and each product is designed and manufactured based on customer requirements [1]. Adopting the OKP model, companies usually have to adapt managerial 
paradigms, business models and ICT supporting tools developed for other (i.e. the repetitive) sectors. Especially from the ICT standpoint, the adaptation of existent tools leads too often to stand-alone applications and a low level of integration among different software, weakly supporting the business objectives.

In OKP environments an effective management of industrial processes, along with an efficient ICT support, may ease companies in optimizing project lead times, minimizing costs and gaining competitive advantage. For these reasons, the main aims of this paper are:

i. to identify and investigate strengths and weakness of the main OKP business processes;

ii. to analyse the ICT support, the level of integration among the different ICT solutions adopted and the ICT functionalities required;

iii. to build a framework that could define and link the main processes in order to obtain a guideline useful for re-engineering the processes and laying the foundation for a new integrated ICT business template for OKP companies;

iv. to carry out a list of functionalities pertaining to the framework's distinct tasks (since one of the final aims of this research is the development of an integrated IT business solution supporting OKP companies).

In order to achieve these objectives, we carried out an empirical research in a number of leading firms in the special purpose machine sector, in which Italy is the fourth producers in the world (7,353 million euro, representing the $7.6 \%$ of the worldwide production), after China, Japan and Germany [2].

The paper structure is the following. In section two are depicted the research questions and the adopted methodology, while section three describes the main findings from the empirical research and the practical framework carried out. Conclusive remarks and directions for future research are drawn in section four.

\section{Research Objectives and Methodology}

The results presented in the next Section 3 of this paper are based on a multiple case studies empirical research, a form of quali-quantitative descriptive research that refers to the collection and presentation of detailed information about a group of companies, drawing conclusions about that group in a specific context [3]. These case studies provide an empirical body of knowledge about the state-of-the-art of information systems supporting the leading processes in OKP companies. According to the purposes of our research, the main research questions have been stated as follows:

- What are the typical OKP companies' values activities (core activities)?

- Which are the more and less supported ICT functionalities? What kind of ICT support is used?

- Which are the functionalities that are perceived by the companies as more critical?

- Which are the less supported processes, both in terms of managerial policies and ICT support? 
Our case-study approach is based on purposive sampling rather than random sampling (see, for example, [4]). In particular, to select the companies, we adopted the judgmental sampling technique, belonging to nonprobability sampling methods that are used for many research projects and are appropriate in case of limited resources and inability to identify exactly the population members [5]. Furthermore, nonprobability sampling may be a practical choice in exploratory research, where the aim of the research is to establish whether a problem exists or not [5]. According to this technique, in our work the sample was based on the researchers' experience, knowledge of the sector and available data, considering the relevance of this kind of companies in Italy in terms of presence on the territory, the overall turnover and employment level, as well as the peaks of excellence reached by many of them in various specific sectors.

In total, 21 companies were included in the sample. Figure 1 classifies sample companies based on the number of employees and the yearly turnover. As mentioned above, these companies mainly belong to the special purpose machines industry, from CNC machine center to customized food packaging machines and automatic assembly line design and manufacturing. This information has been collected by submitting a preliminary questionnaire to these firms, concerning general information about industry, products manufactured, turnover, number of employees, and amount of investments in information and communication technology (ICT). Hence, other specific data were gathered through structured interviews until the achievement of theoretical saturation. The interviews were directed, in first instance, to the entrepreneur and, when present, to project managers and/or CIO. Whenever necessary, other managers of specific areas, such as production, logistics and purchasing were involved in the interviews. In addition, observations at the target companies and informal discussions with engineers were used to gather data, as suggested by Glesne and Peshkin [6]. Finally, the data collected through the interviews allowed to perform some cross-case analyses related to the investigated issues and reported in the remaining of the article.

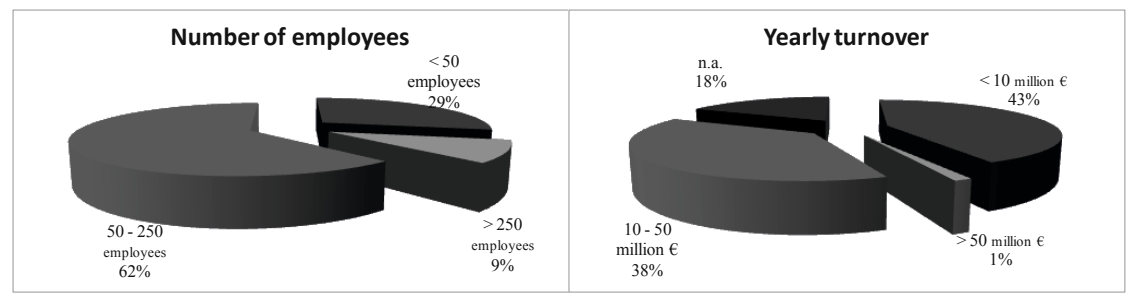

Fig. 1. Classification of target companies based on employees and turnover

\section{$3 \quad$ Main Findings}

\subsection{Results from the Empirical Research}

The analysis of the outcomes of the structured interviews is briefly summarized in this paragraph. Based on Porter's value chain [7], we classified the core activities performed by an OKP-based company into primary and support activities. Thus, we defined "quotation and order management", "technical and commercial 
development”, “design”, "purchasing”, “production, assembly and testing”, “delivery", "commissioning", and "after-sales service" as primary activities, and "project management", "planning", and "cost control" as support activities.

The objective of the interviews has been to analyze whether the activities are structured and governed by procedures and rules inside the companies, and to investigate their ICT support. Thus, for each of the above mentioned activities, Figure 2 shows the percentage of companies that formalizes it, while Figure 3 reports the percentage of companies that support it through the ERP system or an ERP integrated application, and through stand alone applications.

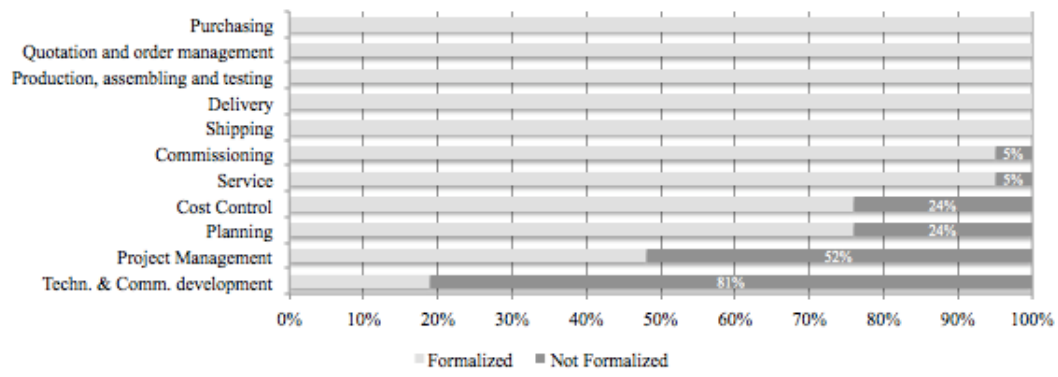

Fig. 2. Formalization level of primary and support activities

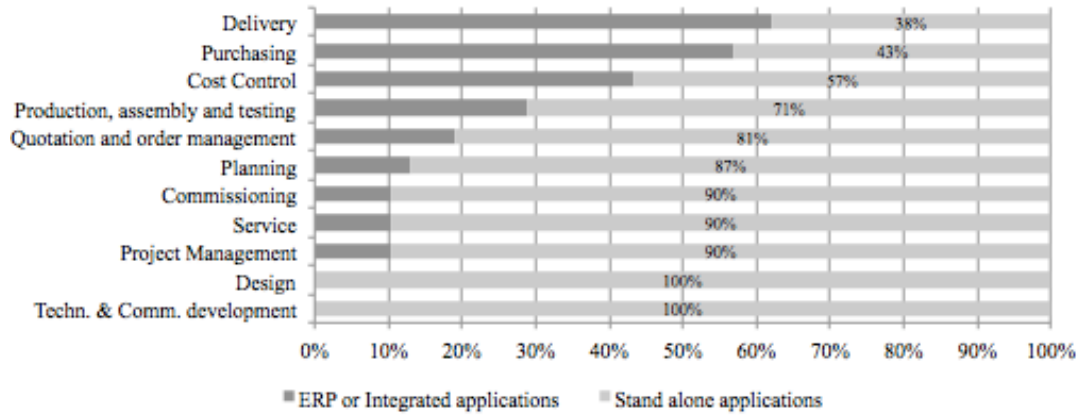

Fig. 3. ICT support of primary and support activities

Figure 2 and Figure 3show that the primary activities are properly structured and governed by procedures and rules, and appropriately supported by ICT tools. On the contrary, the results highlight that three fundamental supporting processes ("project management", "planning" and "cost control") are not well formalized. This suggests room for improvements because these processes may be considered the core of project-based enterprises, since the high customization results in frequent changes of product design, process planning and production routines [8] and resource usage has to be carefully handled and monitored.

In addition, the interviews highlighted a scarce use and knowledge inside companies of methods to carry out project management, planning and cost control; these kinds of activities are usually driven by people expertise (generally managed by the company owner), and an on-going monitoring of order status is often missing. 


\subsection{The Proposed Framework and Functionalities}

With the aim at supporting the development of processes and tools to fill the main gaps highlighted in the previous section, we devised a general, ideal process framework. Such a framework, graphically summarized in Figure 4, encompasses all the tasks supporting the activities described in Figure 2 and Figure 3, resulted as the most critical and less formalized for the involved sample of OKP companies. The support activities are further intertwined with other activities in an ideal flow from the request for proposal to the cost management.

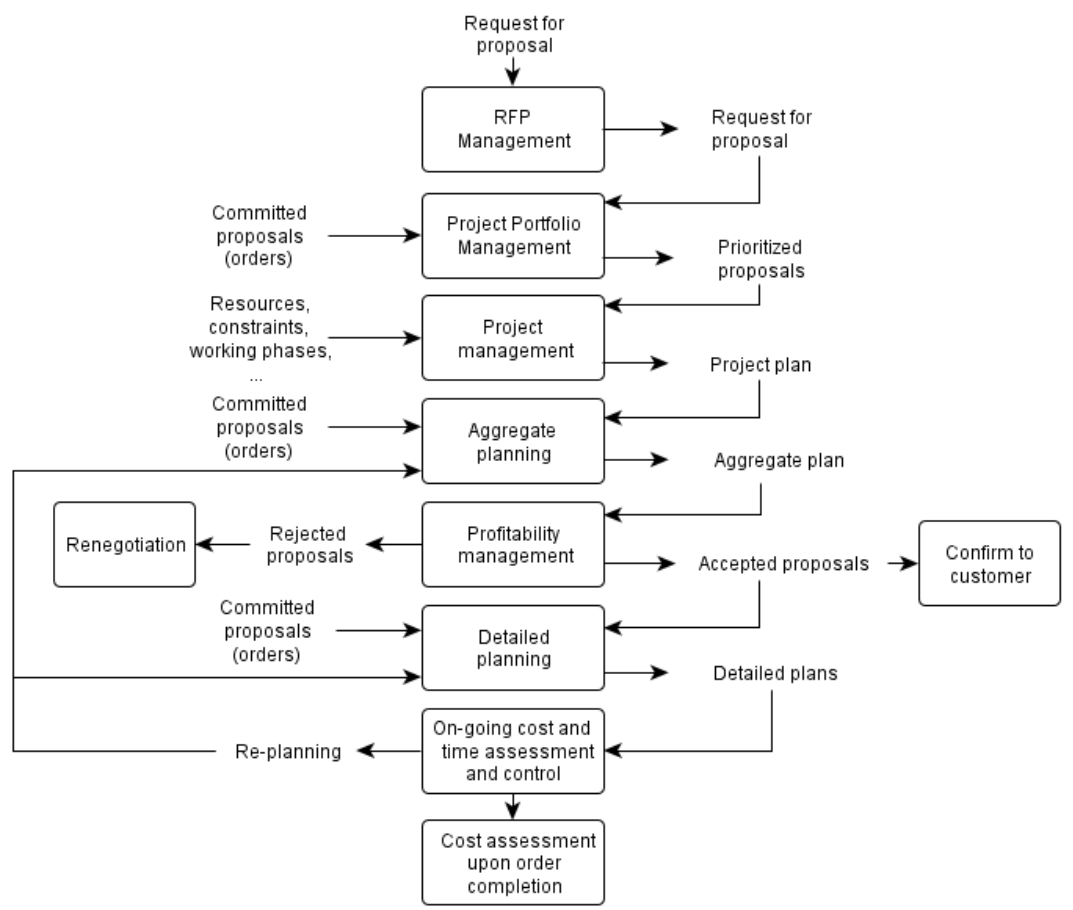

Fig. 4. Process framework

Upon the receipt of a request for proposal (RFP) from a customer, the OKP company evaluates it in order to analyse its technical feasibility, and to come up with an economic offer and an internal priority index (RFP management). This index allows defining the priority of each RFP in comparison with other, already committed orders, based on parameters such as the requested delivery date, the relevance of the customer, the resource requirements, the degree of similarity with other orders, and so forth. The priority index also defines the accessibility precedence to scarce resources. After this activity (also referred to as project portfolio management), each prioritized RFP passes to a project manager, who elaborates a project plan defining all the activities required to realize the final product, and their sequences (project management). 
Each RFP is evaluated independently, considering the production system as empty and all the resources immediately available. In this way, the theoretical amount of resources required to realize each proposal is determined, as well as the hypothetical duration and the delivery date.

All the activities performed so far refer to RFP, and not to committed orders. Up to this point, the RFP is not yet confirmed to the customer. The subsequent step in the framework (aggregate planning) consists in the integration of the RFP with the already committed orders, in order to evaluate the impact of the new, potential order on the production system. Therefore, the main aim of this step is to generate an aggregate plan that incorporates the committed orders and the RFPs, considering the priority indexes, the advancement status of existing orders, the resources availability and so forth. Only after this step it is possible to evaluate and assess the impact of the RFP on the company's system through a profitability management step. The company can now decide whether to accept the RFP (that becomes a committed order) giving the confirmation to the customer, or reject it and return to a negotiation stage with the customer in order to change RFP's parameters such as the general requirements or the delivery date.

Once the RFP has become a committed order, it is possible to process the information at a higher detail level, performing a detailed planning that schedules the activities of the different phases of the whole order fulfilment process (from the design phase until delivery and commissioning) in order to drive the activities in the shortmedium term. The detailed plans are then passed to each phase manager, and the ongoing cost and time assessment and control activity is continuously performed until the product delivery to customer. This on-going monitoring can highlight the need of a re-planning, either at an aggregate or at a detailed level, which can be a consequence of internal or external time deviations or requirement changes. After the product delivery to customer, the cost assessment after order completion is carried out to monitor internal order performance.

Since one of the aims of this research is the development of an integrated IT business solution supporting OKP companies in dealing with multi-project management, activity planning and cost control, we firstly validated this framework with the sample companies and, then, we identified a list of IT functionalities pertaining to the framework's distinct tasks (listed in Table 1). For the sake of completeness we added also the functionalities related to cost control system setup, namely the initial definition of budget items, cost items, allocation drivers and KPI.

\section{Conclusions and Further Development}

Only in recent years, with the affirmation of the mass customization concept, we are assisting to a growing concern (or for some aspects, to a renovate level of interest) for the OKP model, that otherwise can count on a paucity of managerial paradigms if compared to the mass production environment.

In our research, we recognize activities (as defined in [7]) and ICT support as the pivotal elements around which the companies performance are built: therefore, we discussed the results of a multiple case studies empirical research carried out on 21 
Italian companies operating in the special purpose machinery industry aiming at highlighting weaknesses and potential actionable points to improve SMEs results.

As the discussion pointed out, the lack of support of three fundamental tasks such as project management, planning and cost control underlines that there is substantial room for improvement under the ICT support perspective, where entry level solutions seems still far from compliance with OKP operations requirements, and high-end ERP solutions are out of the budget from many SMEs.

Table 1. IT functionalities

\begin{tabular}{|c|c|c|c|}
\hline \multicolumn{4}{|c|}{ IT Functionalities } \\
\hline$\stackrel{\overrightarrow{0}}{\stackrel{0}{0}}$ & $\begin{array}{l}\text { Budget item definition } \\
\text { Allocation driver definition } \\
\text { Definition of cost items and KPI }\end{array}$ & \multirow{4}{*}{ 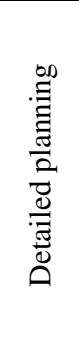 } & \multirow{4}{*}{$\begin{array}{l}\text { Order phases, time, constraints definition } \\
\text { Resources assignment to activities } \\
\text { Available capacity definition } \\
\text { Order phases scheduling (finite capacity) } \\
\text { Multiple detailed planning scenarios } \\
\text { evaluation } \\
\text { Resources loading visualization } \\
\text { Final order activities plan visualization }\end{array}$} \\
\hline 它 & Budget calculation & & \\
\hline 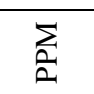 & $\begin{array}{l}\text { Priority criteria definition } \\
\text { Project priority definition }\end{array}$ & & \\
\hline \multirow[b]{2}{*}{ 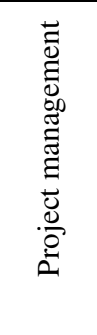 } & Definition of order phases and & & \\
\hline & $\begin{array}{l}\text { constraints } \\
\text { Definition of time, macro- } \\
\text { resources and responsibility } \\
\text { Single order phases planning } \\
\text { (considering an empty system) } \\
\text { Risk management } \\
\text { Order plan sharing } \\
\end{array}$ & \multirow{2}{*}{ 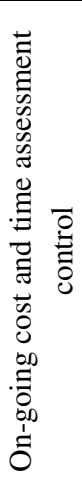 } & $\begin{array}{l}\text { Check order progress } \\
\text { Man and machine hours gathering } \\
\text { Costs assignment to man and machine } \\
\text { hours } \\
\text { Costs allocation based on drivers } \\
\text { Cost deviations calculation and analysis } \\
\text { per single order }\end{array}$ \\
\hline \multirow{2}{*}{ 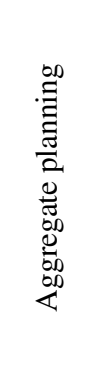 } & $\begin{array}{l}\text { Available capacity definition } \\
\text { Order phases planning (finite } \\
\text { capacity) } \\
\text { Multiple aggregate planning } \\
\text { scenarios evaluation }\end{array}$ & & $\begin{array}{l}\text { Time deviations calculation and analysis } \\
\text { per single order } \\
\text { Deviations resolution suggestion } \\
\text { Order plan adjustment } \\
\text { Reporting (indicators) }\end{array}$ \\
\hline & $\begin{array}{l}\text { Resources loading visualization } \\
\text { Orders' plan sharing } \\
\text { Orders' plan visualization } \\
\text { Re-planning }\end{array}$ & 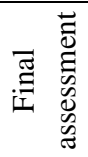 & $\begin{array}{l}\text { Final cost and time deviations calcula- } \\
\text { tion and analysis per single order }\end{array}$ \\
\hline
\end{tabular}

As a result, many activities are still performed in inconsistent ways, using different ICT supporting tools (implying data redundancy and misalignment) or even manually. The development of an integrated IT environment to support (in particular) project management and planning activities, specifically addressed to OKP companies, would help these companies to improve their performance and competitiveness.

This is the reason why we developed a practical process framework that encompasses all the tasks supporting the activities resulted as the most critical and less formalized for the involved sample of OKP companies. We firstly validated this framework with the sample companies and, then, we identified a list of IT functionalities pertaining to the framework's distinct tasks. 
Furthermore, besides the definition of these functionalities, one of the main contributes of this research will be the identification of methods to perform the processes under investigation in an effective way. After a scouting of literature related to project management, planning and cost control, we will come up with a list of techniques suitable to support OKP companies in their order management. Since the aim of this research is to identify methods that can be accepted and implemented by companies, the whole literature review and the final selection will be carried out considering the trade-off between adaptability to the specific context and complexity, in terms of formulation, calculation, and software requirements.

The final step of the research will be the development of an integrated IT business solution supporting OKP companies in dealing with multi-project management, planning and cost control.

Acknowledgements. The study published in this paper has been carried out among the "SIGI-X" project, funded by the Italian Ministry of Economic Development (MISE) under the "Industria2015" framework, project \# M101_00015.

This work does not represent the view of the Ministry or of the "SIGI-X" consortium, and authors are solely responsible for the paper's content.

\section{References}

1. Hong, G., Xue, D., Tu, Y.: Rapid identification of the optimal product configuration and its parameters based on customer-centric product modeling for one-of-a-kind production. Computers in Industry 61(3), 270-279 (2010)

2. UCIMU: Sector report (2010) (in Italian)

3. Yin, R.K.: Case Study Research—Design and Methods, Sage, London, UK (1990)

4. Hameri, A.-P., Nihtilä, J.: Product data management-exploratory study on state-of-the-art in one-of-a-kind industry. Computers in Industry 35(3), 195-206 (1998)

5. Henry, G.T.: Practical Sampling, Sage Publications, Inc. (1990)

6. Glesne, C., Peshkin, A.: Becoming qualitative researchers. Longman, New York (1992)

7. Porter, M.: Competitive Advantage: Creating and Sustaining Superior Performance. Free Press, New York (1985)

8. Tu, Y., Dean, P.: One-of-a-kind Production. Springer, London (2011) 